\title{
CHARACTERISTICS OF FALLS AMONG THE ELDERLY DURING THE COVID-19 PANDEMIC LOCKDOWN: COVID-19 FALLS AMONG ELDERLY
}

\author{
Isha Tajane, Julia Jossy, Priya Gupta, Prachi Jadhav \\ KJ Somaiya College of Physiotherapy, Mumbai, India
}

Correspondence: gupta.pm@somaiya.edu

\begin{abstract}
BACKGROUND:

Every year millions of older people experiences a fall. There are many reasons associated as to why a fall occurs in elderly: musculoskeletal weakness, balance issues etc. A fall can lead to a serious injury or mortality depending on the type and impact of the fall. As the environment for the elderly was restricted to their homes during the Covid-19 pandemic, this study aimed at assessing the characteristics of falls during the pandemic.
\end{abstract}

\section{MATERIALS AND METHODS:}

60 elderly individuals aging 60 years and above participated in the study. This included $36.7 \%$ males and $63.3 \%$ females. A pre-validated questionnaire was used to assess the characteristics of falls.

\section{RESULT:}

Fear of fall was not experienced or was same as before the lockdown however the fall percentage decreased by $7 \%$ during the lockdown.

\section{CONCLUSION:}

Falls among the elderly decreased during the Covid-19 pandemic lockdown.

\section{KEYWORDS}

balance issues, falls, fear of fall, geriatric, pandemic

\section{INTRODUCTION}

Throughout the Coronavirus (COVID-19) crisis, a growing concern has been the hidden "indirect" costs associated with living in a pandemic. Postponed medical appointments, suspended preventative healthcare, and increased mental health problems, can and have had a large impact on both individuals and society as a whole. One overlooked topic within these potential "indirect" costs is the risk of unreported fall accidents during or following lockdown restrictions.

A fall is a multifaceted phenomenon. A fall can be defined as "an unintentional loss of balance that leads to failure of 
postural stability". [1] Fall accidents are the leading cause of injury-related death in adults aged 65+. According to World Health Organization (WHO) global report on falls prevention, people aged 65 years and above fall about $28 \%-35 \%$ in each year and this proportion increases as age and frailty level increase. [2] Approximately one in three adults aged 65+ fall each year and this increases to over half of adults aged $80+$, or those with neurodegenerative diseases, such as Parkinson's disease. The prevalence of falls in India, above the age of 60 years is reported to be $14 \%-53 \%$. [3]

A person's normal gait is an effect of various system like nervous, musculoskeletal, vestibular and sensory system that work in combination. [4] Along with this, concentration and coordination is required to have a proper gait without the risk of a fall. As age advances, it becomes challenging for the older people to carry out things independently, among which falls stand out. Falls in the elderly are common and lead to morbidity and mortality. [5] It can lead to injuries, fractures, decline in self-ability to do routine things, loss of confidence, disability and even death. [5] An episode of fall can lead to person to resort to activity restriction, which in long term may adversely impact both physical and mental health and further increase the risk of falls. [6] It is also a matter of concern as it increases the expenses for health care and affects the behavioural and psychological aspects due to restricted mobility. Falls are classified into accidental falls which are due to environment factors and pathological falls which may be due to an illness or disability and can cause frequent falls.

The biggest predictor of an injurious fall is a previous fall accident. As such, current ageing research emphasises the need to monitor fall risk and engage in early preventative behaviours to reduce known fall risk factors.

These fall risk factors may include balance or walking impairments, physical inactivity, cognitive impairment, certain conditions and medications, anxiety and depressive symptoms, fear of falling, social exclusion and isolation and alcohol use.

The problem is COVID-19 has confined many older and vulnerable adults to their homes for a long period of time and continues to do so as restrictions in certain areas get tighter. The elderly is not able to go for a walk which is important for a healthy state of body and mind. The muchreduced physical activity might have impacted the strength and endurance, confidence and cardiorespiratory sufficiency. Also, they are not much allowed to directly interact with people in fear of transmitting the virus, leading to feeling of loneliness and boredom among them as their social environment gets a drastic change. Prolonged inactivity and reduced musculoskeletal strength might have increased the fear of fall even with the help of assistive devices. This as well as restricted access to healthcare resources during the COVID-19 pandemic, could mean that ongoing fall accidents are not reported and the continued lockdown restrictions may have exposed many older adults to more fall risk factors, such as, inactivity, social isolation, and anxiety.

However, it is currently unclear how restrictions to daily life during the pandemic may affect falls in older adults. On one hand, fall accidents could reduce during this time due to less time spent doing activities outside of the home. However, it is also likely that future fall risk may increase due to less opportunities to exercise, prolonged social isolation, delayed diagnosis of related medical conditions and increased risk of anxiety and depressive symptoms. Due to various psychosocial changes which have occurred during this unprecedented situation, it is of utmost importance to know the prevalence rate and characteristics of falls which could have been different during such circumstances. Considering this gap in current knowledge, through this study we aim to study the falls occurring during the lockdown.

\section{MATERIALS AND METHODS}

It is a cross-sectional descriptive study conducted during COVID-19 lockdown period. The sociodemographic variables used were gender and age which included males and females above 60 years of age who were invited to participate in an online survey. Participation in the study was voluntary and electronic consent was obtained from the participants.

Participants were excluded if (a) they refused to participate in the study (b) were unable to understand English language, (c) had severe functional impairment and mobility restrictions, and d) were unable to comprehend due to cognitive impairment e) severe stroke sequelae or unstable Parkinson's. Sample size was not estimated prior to study. However, a maximum number of participants was desirable and anticipated. 
A questionnaire was developed as part of the study. The questionnaire included demographic details, medical evaluation, physical activity evaluation, details of falls. Participants were asked to fill in their responses in accordance with relevance to their current scenario during lockdown period. A fall was considered as "an unexpected event in which subject finds themselves on a lower level or on the ground. For the characteristics and circumstance of falls, the elderly were asked about the way they experience before a fall, consequences, need and availability of medical attention. The data collected was analysed using descriptive analysis.

\section{RESULTS}

A total number of 87 individuals responded to this online survey. After screening for accuracy and completeness of the responses, a total number of 60 filled forms were included in the analysis. Further analysis was done for these 60 participants using descriptive analysis. Figure 1 shows age-wise distribution of participants. The mean ( \pm SD) age of the participants was 56.95 19.89 - and included $36.7 \%$ males and $63.3 \%$ females.

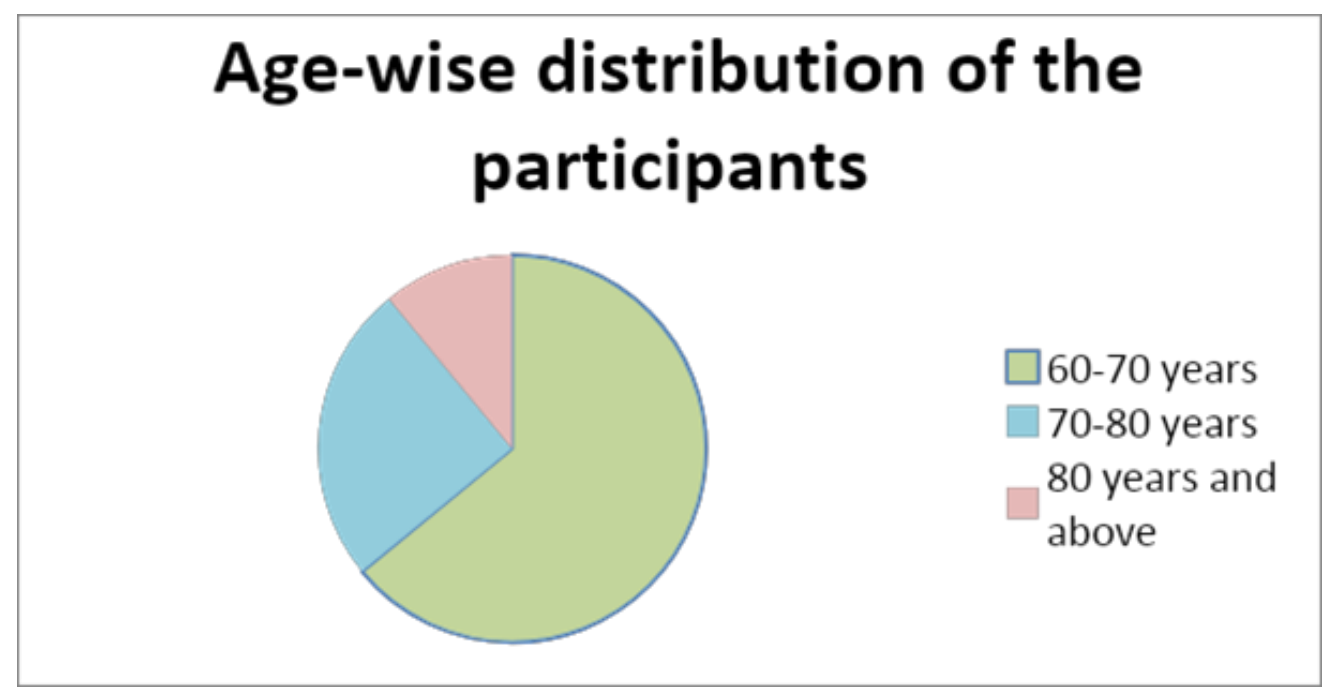

TABLE 1. COMPARATIVE ANALYSIS OF FALL-RELATED CHARACTERISTICS PRE-AND DURING THE LOCKDOWN.

\begin{tabular}{|c|c|c|}
\hline $\begin{array}{l}\text { SR. } \\
\text { NO. }\end{array}$ & PRE- LOCKDOWN & DURING LOCKDOWN \\
\hline 1 & $35 \%$ of people had a fear of fall. & $\begin{array}{l}17 \% \text { of people had fear of fall same as before the } \\
\text { lockdown while } 10 \% \text { of people started experiencing it } \\
\text { during the lockdown. }\end{array}$ \\
\hline 2 & $32 \%$ of people experienced a fall. & The percentage of falls among people was $25 \%$. \\
\hline 3 & $\begin{array}{l}\text { The number of falls people experienced } \\
\text { ranged from once to more than two times. }\end{array}$ & The number of falls experienced was once or twice. \\
\hline 4 & Information is not available & $\begin{array}{l}5 \% \text { people had injuries post fall for which medical } \\
\text { treatment was required. }\end{array}$ \\
\hline 5 & Information is not available & $\begin{array}{l}2 \% \text { people required hospitalization post fall which was } \\
\text { easily available. }\end{array}$ \\
\hline
\end{tabular}


TABLE 2. THE REASONS REPORTED FOR FALL EXPERIENCE DURING LOCKDOWN

\begin{tabular}{|l|l|l|}
\hline SR. NO. & REASON & PERCENTAGE OF PARTICIPANTS \\
\hline 1 & Legs giving away & 40 \\
\hline 2 & Tripping & 30 \\
\hline 3 & Dizziness & 20 \\
\hline 4 & Blackouts & 10 \\
\hline 5 & Accidents and fear of fall & 5 \\
\hline
\end{tabular}

TABLE 3. THE REASONS FOR HAVING FEAR OF FALL

\begin{tabular}{|l|l|l|}
\hline $\begin{array}{l}\text { SR. } \\
\text { NO. }\end{array}$ & REASON & $\begin{array}{l}\text { PERCENTAGE OF } \\
\text { PARTICIPANTS }\end{array}$ \\
\hline 1 & Low confidence level & $18 \%$ \\
\hline 2 & Balance issues & $23 \%$ \\
\hline 3 & Environmental factors like slippery and uneven surfaces & $3 \%$ \\
\hline 4 & Poor eyesight & $3 \%$ \\
\hline 5 & Musculoskeletal weakness & $20 \%$ \\
\hline
\end{tabular}

Activities restricted due to fear of fall:

1. Self-employed activities (8\%)

2. Household activities (15\%)

3. Role as caregiver/grandparents (13\%)

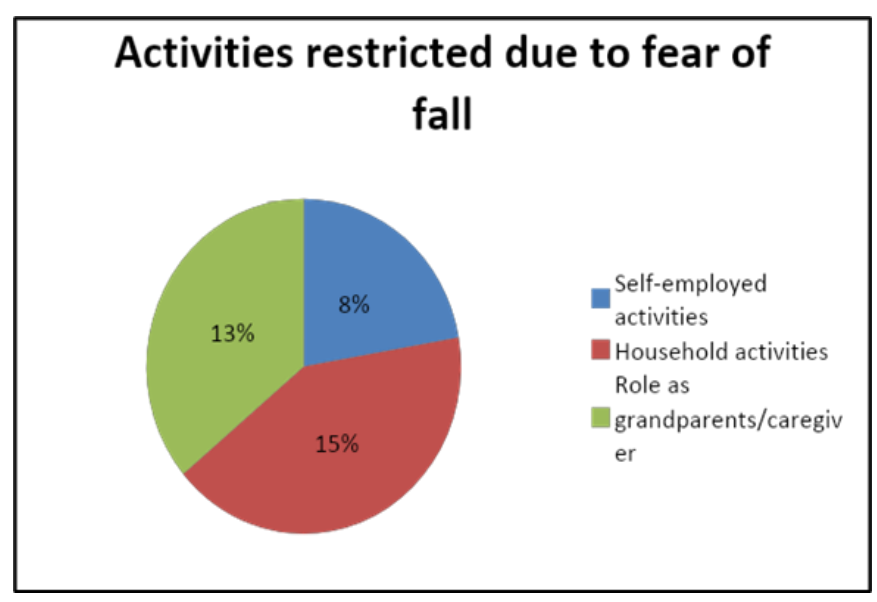

\section{DISCUSSION}

Falls among elderly individuals and the resultant injuries are a major concern from both the financial perspective of health care costs and the psychological and behavioural manifestations associated with restricted functional mobility, physical dependence, and potential life-style changes. Majority of falls are multifactorial and results from a complex interplay of predisposing and precipitating factors. Previous research into the causes of falls among the elderly has been based on a disease-oriented approach that focused on the intrinsic characteristics of the individual [7] or the extrinsic environmental hazards present at the time of the fall. Present study aimed to analyse the falls occurred during the home-confinement period which may reflect the changed intrinsic and extrinsic factors in relation to fall. During this study period, all the falls experienced by the elderly occurred in the home environment. In studies conducted prior to lockdown, falls were most frequently linked to external events. Outdoor falls were more than indoor falls. [8] Most of the studies report the prevalence of falls without specifying the environment in which it occurred. The frequency of falls experienced during the Covid-19 pandemic lockdown was lesser than that before the lockdown. This is consistent with the findings reported by Matthew Hampton et al. in a study on the effects of 
Covid-19 lockdown on the orthopaedic admissions and surgical cases reported across large multi care centres across the UK during this period.[9] The reduction in number of falls after imposition of a lockdown could be attributed to lesser outdoor activities, lesser engagement in sports and outdoor recreation, and lesser mobility on unfamiliar surfaces.[10]

Some other probable reasons for this could be that the elderly were proactive and aware about home modifications and had family support. Moving on reasonably familiar surfaces at home, availability of external support in the form of family members and supportive devices are known to reduce the risk of falls across all age groups.[7] In environments that are well designed or improved with home modifications to support changes in physical abilities, the functioning of older adults can be maximized to facilitate physical health, a sense of security, and continued social engagement with others in the community. $[11,12]$ Fall risk factors are either extrinsic or intrinsic in origin. [11,13-16] Extrinsic factors are environmentally oriented. They include slippery surfaces; inadequate lighting; loose pile, or worn carpets and rugs; staircases without railings; unsupportive or badly arranged furniture; poorly designed tubs, toilets, and fixtures in the bathroom; clutter; and pets underfoot.[11,17-19] Intrinsic factors include health conditions like chronic disease, balance issues, musculoskeletal weakness, impaired cognition, gait disorders, interaction of drugs.[18,20] The home modifications made by the elderly included: staircase railings, bed rails, carpet in washroom to avoid slipping, safety door with stopper, furniture arranged for support. The presence of home hazards could interact with the physical abilities of older adults. This is supported by evidence that there is a greater reduction in the number of falls with modifications to the homes of more vigorous older adults than of those who are frail. [21] The home modifications work in combination with intrinsic and behavioural risk factors. Behavioural risk factors include performing behaviours that could increase fall risk (e.g., reaching out to an object kept on a high shelf while standing on an unstable surface).

In the current study, family support during the lockdown could have also reduced the incidence of falls. Carers' fall concern plays an important role in the prevention of falls. It influences understanding of fall risk among carers and elders; and determine motivate them to continuously adopt preventive behaviours. [22] Being at home with the family gives them a sense of security. Also, $17 \%$ individuals started with online physiotherapy sessions during the lockdown. Exercise and balance training help to reduce the negative effects of the intrinsic factors. [11] Thus with these results, it can be further emphasized that it is very important to further educate the people for need of modifications at home, to improve awareness among elderly and caregivers regarding falls, education regarding fall prevention strategies, training using virtual platforms, importance of proper exercises and diet. We collected data using an electronic media to avoid face-to-face or physical interaction.

This is an important limitation of this study as it could not include the elders who are not acquainted with English language and social media. Owing to the methodological limitation of the online survey, falls cannot be further analysed as that of accidental or pathological category. Also, we attempted to probe into the causative factors of falls, however this information could be subjected to reporter bias in terms of perception and memory bias too. Nonetheless, this study reinforces the findings from previous studies related to causative factors. This study sample of elderly is representative of community-dwelling elderly free from major illness. We suggest further studies involving institutionalized elderly; rural population; and among elderly having neurological disorders or diagnosed with mental health issues. This preliminary report provides a starting point for large population-based studies, especially incorporating a longitudinal design. Considering the recency of the pandemic situation, further discussions to these threads will be interesting to follow.

\section{CONCLUSION}

On the contrary to our presumption that falls and fear of fall might have increased during the lockdown, results of this study show that the incidences of falls and fear of fall have significantly reduced during the Covid-19 pandemic lockdown in community-living elderly. Through this study some protective aspects of home environment in terms of social support are highlighted. Also, elderly individuals' awareness of fall prevention strategies; and importance of physical activities and mental health should be further emphasized. 


\section{References}

1. Narinder Kaur Multani, Satish Kumar Verma: Principles of Geriatric Physiotherapy, 2008, Jaypee

2. WHO Global Report on Falls Prevention in Older Age. 2007 https://extranet.who.int/agefriendlyworld/wpcontent/uploads/2014/06/WHo-Global-report-on-fallsprevention-in-older-age.pdf

3. Pothiraj Pitchai, Hiral Bipin Dedhia et al., Prevalence, risk factors, circumstances for falls and level of functional independence among geriatric population - A descriptive study, Indian Journal of Public Health, Volume 63, Issue 1, 2019

4. Walter Pirker, MD and Regina Katzenschlager, MD: Gait disorders in adults and the elderly, Wien Klin Wochenschr. 2017; 129(3): 81-95.

5. KE Anderson: Falls in the elderly, J R Coll Physicians Edinb 2008; 38:138-43

6. Nandini Deshpande, PT, PhD, Jeffrey Metter, MD et al., Interpreting Fear of Falling in the Elderly: What Do We Need to Consider?, J Geriatr Phys Ther. 2009; 32(3): 9196. PMCID: PMC2954585 NIHMSID: NIHMS237551

7. R.L Berg: Falls in older persons: Risk factors and prevention, 1992

8. O'Loughlin JL, Boivin JF, Robitaille $Y$, et al. Falls among the elderly: distinguishing indoor and outdoor risk factors in Canada. J Epidemiol Community Health. 1994:48:488-489.

9. Matthew Hampton, Matthew Clark, Ian Baxter, Richard Stevens, Elinor Flatt, James Murray, Kevin Wembridge: The effects of a UK lockdown on orthopaedic trauma admissions and surgical cases, Bone Jt Open. 2020 May; 1 (5): 137-143.

10. Data | What is the effect of India's coronavirus lockdown on people's mobility? The Hindu April 06, 2020 https://www.thehindu.com/data/data-what-isthe-effect-of-indias-coronavirus-lockdown-onpeoples-mobility/article31265439.ece

11. Jon Pynoos, PhD,* Bernard A. Steinman, MS, and Anna Q.D. Nguyen, OTD, OTR/L: Environmental Assessment and Modification as Fall-Prevention Strategies for Older Adults, Clin Geriatr Med. 2010 Nov; 26(4): 633644. doi: 10.1016/j.cger.2010.07.001
12. Pynoos J, Caraviello R, Cicero C. The anchor in agingfriendly communities. Generations. 2009;33(2):26-32.

13. Bath PA, Morgan K. Differential risk factor profiles for indoor and outdoor falls in older people living at home in Nottingham, UK. Eur J Epidemiol. 1999;15:65-73.

14. Bueno-Cavanillas A, Padilla-Ruiz F, Jiménez-Moleón JJ, et al. Risk factors in falls among the elderly according to extrinsic and intrinsic precipitating causes. Eur J Epidemiol. 2000;16:849-59.

15. Cesari $M$, Landi F, Torre $S$, et al. Prevalence and risk factors for falls in an older community-dwelling population. J Gerontol A Biol Sci Med Sci. 2002;57:M722-6.

16. Graafmans WC, Ooms ME, Hofstee HM, et al. Falls in the elderly: a prospective study of risk factors and risk profiles. Am J Epidemiol. 1996; 143:1 129-36.

17. Clemson L, Cumming RG, Roland M. Case-control study of hazards in the home and risk of falls and hip fractures. Age Ageing. 1996;25:97-101.

18. Pynoos J, Rose D, Rubenstein L, et al. Evidence-based interventions in fall prevention. In: Enguidanos SM, editor. Evidence-based interventions for community dwelling older adults. New York: Hawthorn; 2006. pp. 55-73.

19. Rogers ME, Rogers NL, Takeshima N, et al. Reducing the risk for falls in the homes of older adults. J Hous Elderly. 2004;18:29-39.

20. American Geriatrics Society. [Accessed June 28 , 2010]; AGS clinical practice guideline: Preventing falls in older persons. 2010 Available at: http://www.americangeriatrics.org/health_care_profe ssionals/clinical_practice/clinical_guidelines_recomme ndations/2010/

21. Lord SR, Menz HB, Sherrington CAge Ageing: Home environment risk factors for falls in older people and the efficacy of home modifications. 2006 Sep; 35 Suppl (2): iii55-ii59.

22. Seng Giap Marcus Ang, BSc(Hons), Anthony Paul O'Brien, PhD and Amanda Wilson, MCA, PhD: Fall concern about older persons shifts to carers as changing health policy focuses on family, homebased care, Singapore Med J. 2018 Jan; 59(1): 911.doi: 10.11622/smedj.2018005 